\title{
Durchlauchtigster Kronprinz, Gnädigster Kronprinz und Herr!
}

Ew. Königlichen Hoheit wage ich es gegenwärtigen ersten Versuch einer wissenschaftlichen Beschreibung des gesammten hiesigen Antikenvorraths als ein Zeichen des unterthänigsten Dankes zu überreichen, zu welchem Höchstdero gnädige Beachtung meiner früheren Leistungen mich verpflichtet.

Als ich vor Jahren auf ähnliche Weise die Museen Roms und Neapels beschrieb, ward im Verfolg meiner Arbeit mir das Glück zu Theil, die lebensvollen Trümmer des Alterthums, die mich beschäftigten, Ew. Königlichen Hoheit erleuchteten Augen vorführen, für ein seitdem erfolgreich gewordenes Unternehmen, das Institut für archäologische Korrespondenz, Höchstdero schützende Theilnahme mir erbitten zu dürfen. Die gegenwärtige Beschreibung des aus klassischem Boden heimgeführten Antikenvorraths hätte 
ohne jene von Ew. Königlichen Hoheit begünstigten Arbeiten ihre wissenschaftliche Begründung nicht erhalten können; sie wird an gedeihlicher Wirkung ihnen nicht nachstehen, weǹn Ew. Königlichen Hoheit gnädiger Antheil dieser, wie jenen früheren, schützend und begeisternd zu Statten kommt.

In tiefster Ehrfurcht verharrend

\author{
Ew. Königlichen Hoheit
}

unterthänig gehorsamer

Berlin, 30. Juni 1836.

Ed. Gerhard. 